\section{VIBRATIONS OF AIR PRODUCED BY HEAT}

DURING the past session an interesting experiment $w$ as made by some students of the College of Physical Science, Newcastle-on-Tyne, engaged in their practical course of chemistry in the laboratory, sufficiently striking and remarkable to secure it, I have little doubt, a short notice among the records of a scientific journal. While testing the inflammable properties of the explosive mixture of air and coal-gas proceeding from the mouth of an unlighted Bunsen-burner, and observing its flame kindle and flashing back along a glass tube, it occurred to one of the students and to the chemical demonstrator, Mr. Haigh, to check the flame in its descent by inserting a piece of wire-gauze in the tube. On reaching the wire-ganze the flame rested there, as they expected; not silently, however, but bursting to their surprise with remarkable clearness and loudness into the peculiar singing strain of the chemical harmonicon. Mr. Haigh made several experiments on the flame with tubes of different sizes, which, if more immediate engagements had not prevented me from pursuing them, it had been my intention to have varied, and to have examined them more completely. In the form in which it first presented itself, a convenient and easily intelligible arrangement of which is here sketched, it appears, however, to offer all the attractions and the remarkable strength and variety of singing proverties with which it seems to be abundantly endowed. A cylindrical lamp-glass mounted with a cork and wire-triangle on a Bunsen-burner serves to shield the mouth of the tube from draughts of air, and to preserve a steady flow of the entering gas. The tube is first lowered over this and lighted at the top; by raising it gradually sufficient air soon enters with the gas below to make the flame waver on the top of the tube, and finally descend to the wire-gauze, where it then burns most vociferously, especially if the wire-gauze is placed at the best position in the tube to produce some of its harmonic notes. The highest notes are sounded when it is above the middle, or even near the top of the tube, and the lowest when it is not far from the bottom of the tube; the stronger draught arising from the long column of heated air, which soon greatly assists the sound, appearing in the latter case to favour the production of notes of the deeper pitch. A glass tube about $2 \mathrm{ft}$. long and nearly $\mathrm{x}$ in. in diameter inside furnished a very powerful note, the wire-gauze being placed a short distance below the middle of the tube. By bending down the edges of a square or circular piece of wiregauze over the flat end of a round ruler so as to fit the tube correctly, all passage of the flame between it and the tube is prevented, but when, as quickly happens with the increasing hect and updraught of the tube, the agitation of the flame grows more and more intense, it at lenuth red-heats the wire-gauze, and passing through it lights the Bunsen-lamp below. A very instructive illustration is thus afforded of certain conditions in which the security of Davy-lamps in a fiery atmosphere can no longer be assured, where a sufficiently quick draught, or in this case the pressure of continued vibrations, carries the flame against the meshes of the wire-gauze until they are ignited. In one case danger arises of the wind carrying the flame of one side of the interior of the lamp over to the other side, which it redheats; in the present case the vibrations carry the flame back upon itself. If in the former case a red-heated Davy-lamp is not turncd round quickly to face the draught, explosion does not always follow; but in this case the current of explosive gas is immediately presented to the heated gauze, and not having undergone any previous combustion it is of course quickly kindled. On the other hand, another source of insecurity of safety lamps when exposed to sudden vibrations, or to the shock produced by a fall, is well shown, when it sometimes appears to happen, if the flame flutters very strongly, that it strikes through the wire-gauze without red-heating it, and lights the lamp below. This may, however, have occurred from imperfect fitting of the wire-gauze to the sides of the tube, and it would be interesting to repeat it if possible with precautions for making the surrounding junction quite secure. A lighted Davy-lamp suspended by a wire in a tin tube $3 \mathrm{ft}$. or $4 \mathrm{ft}$. long and wide enough to admit it easily, through which a stream of coal-gas mixed with air was passing made the tube hum very loudly, but no explosion followed, perhaps because it was not found possible to produce in the lamp a sufficiencly violent agitation of the flame. A remarkable example of the ease with which the wire-gauze flame excites the notes of even very short, wide-mouthed tubes can easily be shown by inserting a well-fitting piece of wire-gauze I or 2 in. from the lower end of a straight lamp-glass, as shown in the sketch, and supporting this a few inches above an un- lighted Bunsen jet. When the gas is lighted on the top of the wire-gauze and the heat of the glass chimney becomes sufficient to increase the draught, which may also be adjusted by varying the gas supply to the glass, its shrill treble note is sounded at once with overpowering loudness. The sensitiveness of the wire-gauze flame to acoustical impressions was, I believe, demonstrated very recently by Prof. Barrett, by many new and striking experiments on the depression of its luminous cap or top in obedience to the voice and to other sounds; and I have been assured both by Prof. Tait and by Prof. Marreco that the use of the smokeless wire-gauze burners, common in laboratories before the introduction of Bunsen's lamps, for exciting the hoarse music of singing flames in tubes of large calibre has long been familiar to them as a thoroughly effective means of reproducing the chemical harmonicon with common coal-gas. The easily inflammable nature of well aërated coal-gas combined with the conducting and quenching power of wire-gauze on flames which ir supports, supplies an obvious explanation of the responsive vibrations of the flame to any description of rhythmical surrounding agitations and impulses. I was not, however, prepared for an equally remarkable and peculiar property of heated wire-gauze to the above, which, like the last experiment, was also shown to me by Mr. Haigh in some of his trials of the sounding tubes. When the flame had been sounding strongly and the gas was turned off

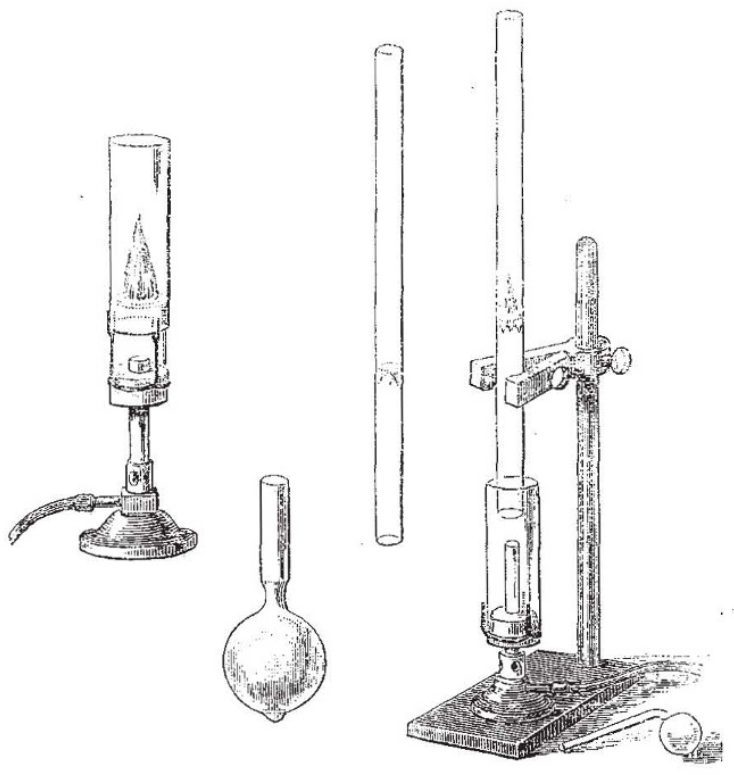

to extinguish it, instead of ceasing immediately the musical note continued for a considerable time, sometimes even gaining a little in strength before it died away, the tube then appearing to have the power of intoning spontaneously without the presence of any visible exciting cause. That the source of these prolonged vibrations is the heat communicated to the wiregauze, which enables it to expand the air by impulses in the tube as the ascending current gradually passes through its meshes was confirmed by a variety of experiments, all pointing to this origin of the sound as its real explanation. It happened on one occasion, when the flame passed through the gauze, lighting the Bunsen-lamp below, and leaving the gauze red-hot, that on putting out the lamp the after-note sounded so long and loudly as quite to equal, if it did not even surpass what had just been emitted by the flame. To reproduce the same note it is in fact only necessary to red-heat a wire-gauze diaphragm inserted a few inches above the lower end of a pretty wide glass tube over a Bunsen-flame, and to remove it from the lamp. when the gravest note of the tube will immediately be sounded with all the strength and purity that can be desired. Somewhat coarser wire gauze than that used for the singing-flame succeeds the best, as, besides being more easily red-heated by the Bunsen-flame, it furnishes a larger store of heat to the ascending air-current, which, in passing through its meshes, produces the singing sound. If the tube is raised quickly, the draught through it being thus checked it stops, and as soon as it is brought to rest 
it begins to sing again; by lowering it quickly the note is much strengthened, as it is also by turning on an unlit gas-jet under it, and especially by swinging the tube round horizontally, the lower end foremost through the air, which increases the draught and the strength of the note most considerably. The note is silenced when the tube is held at rest inverted, or horizontally, but it begins again as soon as the tube is restored to its erect position. A closely twisted coil of thin platinum wire was compressed in the tube in the place of the wire gauze, and was made red-hot over the Bunsen-flame, which was then extinguished, and the gas again turned on immediately, causing the platinum wire to continue to glow by catalytic action. As long as its red-heat continued, the musical sound of the tube also continued to be produced. A glass tube $2 \mathrm{ft}$. long by $\mathrm{I}_{4}^{1}$ in. in diameter, stopped near one end with platinum wire-gauze, to the centre of which a small piece of spongy platinum is fastened, performs in this way over an unlighted gas-jet, when started by preparatorily heating the platinum gauze, for any length of time. Although unable to do so over ordinary coal-gas, yet it is very proibable that over hydrogen (as a heat below redness is sufficient to maintain the sound) a tube thus fitted with pieces of platinum sponge laid upon wire-gauze would start and continue to sound by itself.

When a glass bulb is blown at the end of a glass tube it frequently happens that in cooling it emits a very clear and distinct humming sound. The note has appeared to me considerably graver than what would be expected from air vibrations in the small bulbs in which it occasionally occurs; thus in blowing the small candle-bomb, shown of its proper size on the left hand in the figure, a very loud note, of apparently about middle.C pitch, or even lower, accompanied its cooling. In drying the glass bulb of a broken Wollaston's cryophorus, shown with its bent tube on the right in the sketch, by warming it very gently over a gas-flame to expel some adhering moisture, I was startled on removing it from the flame to hear the same humming note, although the bulb was scarcely hotter than could be touched with the hand, resembling in pitch (although its softness may have had a misleading effect upon the estimate) one of the lowest bass notes of an organ. Being familiar with the depth of tone obtainable with Helmboltz's spherical resonators, I am led to suppose that the combination of a bulb with a tube may have a much lower fundamental note than either of those cavities would have alone. But the acting source of the note requires also to be considered, and if, as appears evident, low beats and resultant tone; cannot be reinforced without strengthening their primaries, the deep pitch of bulb-emitted notes may possibly arise from the nature of the air impulses by which they are produced. These appear to be of the same kind as the air-oscillations in the hotgauze harmonicon. As the energy of the sound-waves cannot be produced without a corresponding motive cause, in the latter it is the ascending current of the rarefied, and in the former the in-draught of the contracting air, both produced by the dissipa. tion or appropriation of a certain store of heat. The cold air entering the hot bulb or ascending through the heated wire meshes, expands in doing so, recoils upon itself, and throws the air column of which it forms a part into vibrations, which continue as long as the flow of air and heat together continue to support the motion. The rapid succession of explosions of the gas-flame harmonicon are, in fact, reproduced; the expansive force of the small puffs or explosions that produce the sound being merely derived from a limited stock of sensible heat, instead of from a constant supply of heat of combustion. Considering the volume and duration of the sound long after the wire-gauze has ceased to be visibly red-hot, the energy of the effect produced by the heated gauze seems to be out of all proportion to its magnitude; but the eflects of the mechanical irinsformation of heat are, as is well known, always sufficiently startling, and sometimes even prodigious when the conditions under which it takes place are at all favourable to the process of the transformation.

I was not aware, when writing this descriplion, that musical sounds produced by heating glass bulbs had been examined so long ago as the beginning of this century, as described in Prof. Tyndall's work on Sound, by the late G. De la Rive, who obtained them by boiling water in thermometer bulbs. The vapour in its passage along the tube is condensed, and by the coliapse that accompanies its contraction throws the air column in the tube into vibration; this action is thus exactly the opposite of what occurs when fresh-blown strongly heated glass bulbs are allowed to cool, the expansion, instead of the contraction, then. giving the necessary impulse. I am also disposed, since reading Prof. Tyndall's description and explanation, to ascribe the low note of the warmed cryophorous bulbs to the escape of aqueous vapour from it in the manner of De la Rive's experiment, rather than to the influx of cold air into the bulb to which $I$ attributed it at first.

It is well known that at a nodal point of a vibrating aircolumn there is no oscillation, but alternate expansion and contraction of the air, while in the middle point of a vibrating seg. ment the opposite is the case. Neither of these places is accordingly a suitable one for the combined air-pressures and oscillations to take place, which in a sounding flame or at a heated diaphragm can never occur separately or independently of each other, the strength of each little puff or explosion depending at once upon the direction and amount of the contributing oscillation; the position of the heating cause must accordingly be between the ventral and the nodal points. It is the same with the air.currents that excite the vibrations of a flute, railway whistle, common bird-call, or organ-pipe; the oscillations and throws of pressure of the air at the embouchures are not only simultaneous, but they must also be so related to each other that an inward oscillation accompanies increase of pressure, since a part of the blast is then thrown into the air-column and compresses it. From an easy law connecting together the changes of pressure with the motion of the air at any point of a staionary air-wave, it appears that in these instruments, exactly as in the hot-bulb, or in the hot-gauze and gas-flame harmonicon, the ventral point (as far as a true one exists) is not at the embouchures of the wind-instruments, nor at the heating and cooling points of the several kinds of heat-sirens or harmonicons, but outside of them in such a position as to place the exciting air-puffs between the nodal and the ventral point. Prof. Tyndal has truly pointed out in his sound lectures that whenever stationary undulations are kept up against friction, as when a stretched string is kept in uniform vibration by the hand, the nodal points are not absolutely stationary points, but present a little oscillation. It is equally true that the string does not remain accurately parallel to itself where it ought to show true ventral points, and accordingly resists a hand applied there to keep up its oscillations with a certain force; but this resistance is weak, and it acts through a wide excursion, while near the nodal points the necessary efforts of the hand are greater and exerted through very small displacements. In intermediate positions the nearer the string is held to a nodal point, and the smaller its excursions, the stronger must be the jerks given to it by the hand to keep up its oscillations. In air-instruments (including the harmonicon and flute) the jerks of the hand correspond to the explosive force of the small admitted puffs of air, depending in heat-harmonicons on the intensity of the heat or combustion, and also on the quantity of the matter burned or heated in the successive puffs; and in wind-instruments no doubt principally on the pressure and perhaps to some extent also on the quantity of the admitted blasts. According to the position of the em. bouchure (including a flame-jet or a heated gauze under the ex. pression) in the vibrating segment of a wave of resonance, its beneficial action in maintaining the air-wave will be evoked or suspended in obedience to the particular conditions that exist in the air-wave at that point ; the only absolute requirement for its activity being that entanglement of a fresh supply of blast must coincide with a moment of rising pressure at that point of the air-wave. This is easily accomplished in wind-instruments, the large excursions of the air at the embouchures ensuring a plentiful introduction of the entering wind-puffs at the proper time; the action in this case is quite free from complication, as without considering the small gains of pressure periodically given by the blast as it flows inwards, and a small suction that it exercises (to which I believe that Mr. Hermann Smith is the first to draw attention in his excellent communication on this subject in NATURE, vol. x. p. I6r), as it retreats, nothing prevents the to. and-fro displacements at the mouth of an organ-pipe from so deflecting the current of the air-blast inwards and outwards as constantly to apply its useful energy to the best effect. Inward motion of air towards a node is accompanied by rising and outward motion by falling pressure, and as the losses of both of these kinds of energy are properly renewed by the blast in entering or retreating, the resonance of the wind-instrument is kept up. The friction and loss of energy in high harmonics is probably much greater than in graver notes, and, the air-excursions being also smaller, it is perhaps on this account that a stronger blast or a nicer direction of it by the mouth-piece 
is found necessary to produce and to maintain them. In heatharmonicons the action is less simple, the alternations of pressure as well as the oscillations of the air determining the admission of the entering puffs. To judge from the position in which a singing-flame sounds best in a chemical harmonicon, a certain "lead" like that used in admitting steam to the cylinder of a steam-engine is necessary for the flames to exert their expansive force, the gas perhaps not instantly igniting on its emergence from the jet; and this "lead" "the mere oscillations of the surrounding air are unable to supply; but in the position which the jet occupies in the tube, the air-pressures, which return at periods answering to a half stroke of the flame before the oscillations, precipitate its development and enable it to exert its pressures at the proper times. The proportion of lead given to the flame increases as it approaches the middle of the tube, where only the variations of pressure act upon it, while at the lower end of the tube it is commanded entirely, like the air-blast of an organ-pipe, by the oscillations of the air. It is perhaps thus that a wire-gauze flame burning at the foot of a lamp-glass sounds so vociferously, because stationary alternations of pressure in the lower part of the tube cannot affect the transmission of gas through the gauze, while the extensive oscillations there produced have perfectly free action in extinguishing and replenishing the flame. By using a piece of thin glass connecting-tube about $4 \mathrm{ft}$. long, held vertically over an unlighted Bunsen jet, on lighting the gas escaping at the top, and carefully raising the tube so as to allow the flame to descend very slowly, it may be made to pause in its descent at the successive ventral points corresponding to the harmonic divisions of the tube, sounding the note of the section of the tube above it as it comes to each point of rest. On lowering the tube it ascends, stopping and singing at some higher point of rest, depending apparently upon the less instantaneous inflammability of the gas. With some difficulty, and by shielding the lower end of the tube as much as possible from draughts, the flame was sometimes made to drop quickly within a few inches of the bottom of the tube, stopping always at the same place and sounding there for a moment the lowest note of the tube, when by the strength of its vibrations it was either rapidly extinguished, or else lighted the Bunsen lamp below. The notes sounded by these means were, however, not nearly so loud and effective as those obtained when the gas-flame was held at its stationary points by making it come to rest upon wire-gauze.

I am indebted for almost all of the foregoing experiments to Mr. Haigh, who was very skilful in suggesting and devising modifications of them, leading to the immediate conclusions regarding the mode of their production to which they appear most distinctly to conduct. Other occupations have hitherto prevented me from attempting to extend and to examine them as thoroughly as they seem to deserve; but the field of research presented by the study of harmonic flames does not yet appear to be nearly exhausted, and the repetition of the above experiments by others will perhaps throw more light upon the doubtful questions with which they are still to some extent surrounded, enabling, it may be, the many significant and easily-recognised features of singing flames to be produced with even more than their present ease and certainty.

A. S. HerscheI

\section{SCIENTIFIC SERIALS}

The Geological Magazine, July. - In this number Mr. J. Croll commences an article On the physical cause of the submergence and emergence of land during the glacial epoch, which is to be continued. As far as it goes it is concerned with the conceptions we have of the thickness of continental ice. An attempt is made to estimate the thickness of the great antarctic ice-cap, about which "observation and experience to a great extent may be said to be a perfect blank." The condition of the interior of the antarctic continent is inferred from the little that we know of Greenland. The diameter of the ice-cap being taken at 2,800, the thickness at the centre is given at the lowest at 6 miles, reckoning a quarter of a degree only as the slope of the upper surface. Mr. Hopkins has recorded that he found one degree the least slope on which ice will move. An ice-cap of only 6 miles in thickness is to many an unfamiliar idea, and "few things," Mr. Croll writes, "have tended more to mislead geologists in the intexpretation of glacial phenomena than inadequate conceptions regarding the magnitude of continental ice." - The other original articles are On the dawn and development of life on the earth, by H. Woodward, F.R.S.--Notes on carboniferous monomyaria, by R. Etheridge, jun.-The geology of the Nottingham district, by Rev. A. Irving.--There are two letters on the glaciation of the south-west of England, by Dr. Mackintosh and H. B. Woodward.-Mr. Mallet writes that he does not see how he can be charged with " misapprehending " $\mathrm{Mr}$. Scrope in the discussion on the nature of volcanic heat, and asks that as he has reduced his own views to clear definition (Phil. Trans., vol. i. I873) Mr. Scrope will do the same.

Bulletin de l'Academie Royale des Sciences, Esc., de Belgique, No. 5.-M. Van Beneden contributes the first part $165 \mathrm{pp}$. in length) of a paper entitled "On the original distinction between the testicle and the ovary; the sexual character of the two primorial layers of the embryo ; the morphological hermaphrodism of an entire 'individual' ; an essay on the theory of fecundation." The "essay" opens with an introduction in which reference is made to Huxley's first pointing out that the organism of Zoophytes, Medusidæ, Polyps, Siphonophora and Hydroideæ consists essentially of two layers, endoderm and ectoderm, and also to other writers who have studied the relationships of endoderm and ectoderm in various aspects. The second part contains the history and bibliography of the subject, and the third (5o pp. long) describes the author's researches on Hydractinia echinata, made during a lengthened visit to Ostend. He first describes the characters which the male and female reproductive zooids have in common, and carefully details his methods of prepara. tion. The microscopic description of the female and then of the male zooids or gonosomes is given in much detail, illustrated by plates. He arrives at the following conclusions:-The ovaries are developed entirely from the epithelial layer of the endoderm. Up to the time of maturity they remain entirely surrounded by the elements of the endoderm. The testicle and spermatozoa are developed from the ectoderm. The female sporosacs contain rudimentary testicular organs, and male sporosacs a rudimentary ovary. From a sexual point of view the ectoderm and endoderm have an opposite signification. If it is true that special organs have resulted from specialisation of function following division of labour, then we must believe that originally the whole ectoderm performed the male sexual function and the endoderm the female. The ectoderm is the animal and male layer, the endoderm the vegetation and female. Fecundation consists in the union of an egg, the product of the endoderm, with the product of the ectoderm, which brings chemical compounds of "opposite polarity "into union. "The new individual is formed at the instant the elements of "opposite polarity" unite just as a molecule of water is formed by the union of atoms of hydrogen and an atom of oxygen.-M. Henry contributes papers on chloral and chlor-ethylic ethers, \&c.-M. F. Plateau has sent in a communication on the digestion of insects, which is to be published in the memoirs.

Bulletin de la Socieié d"Anthropologie de Paris, t. vii. - In the seventh volume of this journal $M$. Hamy gives us the results of his examination of M. Janneau's officially conducted investigations into the anthropology of Cambodia. He begins by endeavouring to define the meaning attached to the three words, "Moi," "Kha," and "Penang," which have hitherto been used in Annamite, Laolian, and Kmer almost indiscriminately to indicate the wild tribes of the hills. By the first of these we must understand the negro tribes occupying the oriental chain of the Cambodian range; in the second a people not unlike the yellow races of Laos; and in the third the tribes in whom the flat-faced non-Caucasian type is strongly marked. The Cambodians themselves distinguish between races, known as Kuôi, who, they say, are the primitive people of the land but not savages, and the Rodê, the former being employed in the extraction of the ores of Kompong. Svai, and the latter in the breeding and care of horses, while both are exempt from the yoke of slavery which presses heavily upon nearly all the other tribes. In the Cambodian language M. Janneau thinks he can trace evidence of identity with many of the primitive forms of the roots of the mother-tongue of the Indo-European languages. The Aryan name "Rarna" appears among the ancient regal titles of Cambodia, and while the Sanscrit "Ramayana" includes the Cambodians amongst the offspring of the immaculate cow, Cabala, the people themselves have from the most remote antiquity made the cow the object of special adoration.-The question of the depopulation of certain districts, more especially in the Polynesian and other Australasian insular groups, has lately attracted especial attention among the members of the Anthropological Society of Paris, The Gambier Islands, which in 